Edith Cowan University

Research Online

ECU Publications Pre. 2011

$1-1-2010$

Towards a Corporeal Aesthetics of Plants: Ethnographies of

Embodied Appreciation Along the Wildflower Trail

John Charles Ryan

Edith Cowan University

Follow this and additional works at: https://ro.ecu.edu.au/ecuworks

Part of the Life Sciences Commons

10.1080/10304312.2010.489721

This is an Author's Accepted Manuscript of: Ryan, J. C. (2010). Towards a Corporeal Aesthetics of Plants:

Ethnographies of Embodied Appreciation Along the Wildflower Trail. Continuum: Journal of Media \& Cultural Studies, 24(4), 543-557. Available here

This Journal Article is posted at Research Online.

https://ro.ecu.edu.au/ecuworks/6539 


\section{Towards a Corporeal Aesthetics of Plants: Ethnographies of Embodied Appreciation along the Wildflower Trail}

\section{Introduction: Plant Corporeality and Ethnography}

Banksia are iconic of the Southwest of Western Australia, a region known for a flora that, through a variety of unique ecological adaptations, has become well-suited to intense periods of dryness and nutrient-poor soils. A walk with Kevin Collins, proprietor of Banksia Farm in Mt. Barker, W.A., is an exercise in bodily-engaged multi-sensory appreciation of Banksia. Rather than austere and inanimate, the Proteaceae-the hardy ancient family of plants to which the Banksia belong-are replete with perfumed aromas, enrapturing textures, nectarous tastes and the sound of wind whipping through needle-like leaves. Kevin crushes a handful of plant parts and passes his fist under my nose to inhale 'Proteaceae Perfume', a blend of the aromas of three notoriously prickly species. He speaks of the fragrance jocularly, considering the poetic irony that a family of plants known for its toughness and harshness-plants that symbolise the inhospitable appearance of the landscape-could produce sweet, elaborate, even soft, fragrance.

Kevin's approach to plants could be termed a 'corporeal aesthetics'. His appreciation is not constrained to the visual qualities of the indigenous flora-their spatial assemblage in the garden according to colour and form-but is instead inclusive of their olfactory, gustatory, auditory and palpable characteristics. My walk with Kevin occurred at the nexus of plant and human corporeality and ethnographic enquiry. At this conjunction, I make two distinct but related claims. I first suggest that a corporeal aesthetics of indigenous flora-one that engages the full horizon of human senses in 
response to the bodily presence of plants-is a postcolonial countermeasure to a visually-privileged aesthetics of flora that distances plants from the human observer. My second claim is that the usage of ethnographic practice, specifically participant observation and semi-structured interviewing such as that employed with Kevin, is a pertinent and fruitful methodology for the development of a corporeal aesthetics. The proposed context of 'cultural botany', in which the research is situated, expands upon recent theoretical and practical work in cultural ecology (Head 2007; Head \& Muir 2007; Head \& Atchison 2009), human-plant geographies (Hitchings 2003; Hitchings \& Jones 2004; Seddon 2005) and ethnobotany (for example Martin 1995; Cotton 1996).

Through interviews and participant observation conducted during the 2009 Southwest Australian wildflower tourism season, I argue that a valuation of flora based in sight is a narrowly-circumscribed constituent of a broader aesthetics of embodiment, in which the five senses and the metasenses can be invoked. Towards these purposes, I present two site studies from the Southwest. Considered barren and sterile by early European explorers, the Lesueur-Eneabba region and the Fitzgerald River National Park are places of high floristic diversity and, historically, of low aesthetic value. A reading of aesthetic language in the journals of the early explorers, in the transcripts of contemporary plant experts and tourists, and in contemporary scientific management plans identifies a unifying thread and a monolithic impasse-the visual assignment of value. The Southwest Australian region-one of the most botanically diverse Mediterranean ecosystems in the world, stretching from Shark Bay to Israelite Bay east of Esperance and including metropolitan Perth ${ }^{2}$-when in-blossom, stimulates human movement to sites of notable wildflower irruption (Corrick \& Fuhrer 2002). The Southwest wildflower tourism season is renowned locally, throughout Australia 
and internationally. Visitors with diverse cultural backgrounds and varying levels of scientific expertise arrive each year for the colourful vistas and unusual flowering forms of the region, that is, to have an aesthetic experience of wild, uncultivated flora. Nearly one in five Perth residents visited botanic reserves between 2001 and 2003 to view wildflowers (Western Australian Tourism Commission 2003). Moreover, of the four thousand annual visitors to Banksia Farm, the premier destination for photographing all species of Banksia, nearly two-thirds are from Eastern Australia (Collins 2009). The annual wildflower show in rural Ravensthorpe reports a broad spectrum of visitors from Asia, North America and Europe (Bennett 2009).

My use of an ethnographic approach in putting forth a corporeal aesthetics of indigenous Southwest Australian plants aimed to identify both visual and embodied evaluations of the flora through participant observation and semi-structured interviews. As a participant, I took part in wildflower tourism at the Lesueur-Eneabba region and the Fitzgerald River National Park through tours by bus or car, walks entirely on foot or a combination of walking and driving, and shows or celebrations at churches or community centres. Interviewees were selected to provide a cross-section of expertise from professional and amateur botanists, horticulturalists and wildflower enthusiasts or tourists. Professional botanists like Steven Hopper, are usually academically trained, scientific researchers with a comprehensive grasp of larger scientific patterns. Amateur botanists-Merle Bennett and Allan Tinker-are typically self-trained and specialised in the local flora of their subregion. Horticulturalists, exemplified by Kevin Collins, are skilled in the propagation and cultivation of certain species of indigenous plants. Wildflower tourists, such as Lyn Alcock, are often not necessarily formally trained in 
botany but, through their seasonal travels, often have detailed understandings of species distributions and flowering times across the region.

\section{Visual Aesthetics of Flora: The 'Everlasting' and the 'Orchid' Effects}

The flowering orchids of the Fitzgerald River National Park are subtle, delicate arrays of intricate colourations and aerodynamic shapes. They beckon the flower-seeker to get down on hands and knees and enter into the corpus of the vegetation, pushing through Daviesias and Melaleucas with the proboscis of a lens. The bold, drooping rose-like blossoms of the Quaalup Bell are elegant and striking, whilst carpets of everlastings, especially in proximity to Morewa and Mullewa in Southwestern Australia, enfold the human viewer in an antediluvian sea of colour. Such carpets of everlasting flowers are predominant in the northern part of the inner Wheatbelt of the Southwest.

The 'everlasting' and 'orchid effects' are modes of visually interpreting plants. Any mass of flowering conveys an everlasting effect in the expansiveness of the view, the accessibility and consistency of the colour, and the oceanic experience of the rippling distance consumed by red, yellow and pink hues. In contrast, the orchid effect in the southern part of the region near Ravensthorpe and the Fitzgerald River National Park requires a subtlety of perception and the willingness to viscerally interact with the bush by bending down and using magnifiers to perceive the architectures of morphologically minute flowers. Kevin Collins summarises the orchid and everlasting effects and consequences of this distinction for regional tourism: 
will head down south thinking, there's better rainfall here, there's a few little flowers in the bush. When it's poor up there, we get more visitors here (Collins 2009).

Although the everlasting effect is the most visually striking and immediately affective, the orchid effect tends to harbour the most botanical biodiversity and species richness and requires of the human observer an engagement of bodies. At places like Fitzgerald River the landscape viewed panoramically from the window of a car appears mostly as a drab olive green, even during the height of flowering in the spring. In other words, the everlasting effect, as a category of visual appreciation, though applicable to some regions of the Southwest, is not a sensitive or compelling approach to the native flora of other locales. Insofar as it challenges the conventions of panoramic visualism and beckons the engagement of the body, the orchid effect, though visually-based, is a segue into a corporeal aesthetics.

Despite contemporary growth in wildflower tourism, Southwest Australian plants have not always been extolled for their beauty or represented as integral to the landscape and human settler activity. As Seddon (2005) remarks 'Appreciation of the unusual quality and beauty of the Australian flora has a long history, but not always a continuous one, and not one that has ever been fully translated into effective conservation practice as the current status of the Banksia genus in Western Australia indicates all too well' (147). Nineteenth century texts often portray Southwest plants as visually crafted artistic objects for the appreciation of discerning human subjects rather than as autonomous forms of life worthy of conservation. For example, British horticulturalist John Lindley published the first significant European account of the flora of the Perth area, A Sketch of the Vegetation of the Swan River Colony (Lindley 1840). This publication endeavoured to identify the potential of select Southwest plant species to become 'horticultural objects' in European gardens. However, the text is 
distinctly disembodied, with only minor reference to the material requirements of the plants, their pan-sensory aesthetic qualities, or the prospects of physical human interaction with them.

Visual appreciation and evaluation of plants, epitomized by the everlasting effect and latent in the orchid effect, is contingent on their artistically pleasing qualities of form, colour, symmetry and balance. Writers such as Lindley evidence a surface-oriented, visual aesthetics in their representation of Southwest plants. The insistence that plants adhere to certain acceptable preferences of sight has led to unfavourable depictions of the Australian bush as mundane or unworthy of appreciation (Giblett 2004), when plants, such as the jarrah, fail to meet conventional ocularcentric tenets of symmetry, grace, balance or colour (Seddon 2005) The aestheticisation of landscapes, primarily through the sense of sight, has been historically problematic as European standards of beauty, picturesqueness or sublimity collide with the divergent ecological realities of Antipodean places such as Australia (Giblett 2004). Concerning the dichotomising of landscape as object and human as subject through the dividing line of aesthetic visualism, Giblett (2004) maintains that 'aesthetics has traditionally been concerned with only the senses of sight and hearing and [therefore] is the means whereby the bourgeoisie secured and maintains its hegemony through the distinction of the subject from the object...' (44). The imposition of aesthetic values, therefore, has been linked to the colonisation of the Australian landscape and the domination of its flora.

Furthermore, the visual assessment of value to landscapes adheres within a hegemonic, universalist science of plants. As Pratt (1992) and Foucault (2002) argue, the systematising of the natural world through the language of Linnaean taxonomy has 
brought about an imperial eye, or a visually structuring gaze. Ocularcentrism in aesthetic terms is then closely bound to the scientific imperative to impose order on perceived ecological disarray, ascertained straightforwardly through the outward appearance of plants (i.e. prickly, ugly, mundane). Nowhere is this more evident than in early European settler accounts of the bizarre, disorderly and contradictory vegetation of Southwest Australia, a flora which continues to confound scientific and European aesthetic parameters of behaviour (for discussion, see Seddon 1971; 2005). Textual and visual representation, allied to scientific botany, disavows human and plant bodies and rejects the nuanced sensory presence of plants, as evident in the abstract construct of a 'species' on which much botanical knowledge depends (Ryan 2009).

Sensory experience through the corporeal sensorium has been subjected further to both hierarchical ordering and narrow definition consistently throughout the history of Western aesthetic philosophy. Aristotle correlated the four senses to the four elements-touch with earth, sound with air, vision with water, and smell with fire-and considered taste a variant of touch (Connor 2008). Hegel excluded taste, smell and touch from the sensuous experience of art for their contingency on the gross domain: 'smell with material volatilization in air, taste with the material dissolution of substance, and feeling with warmth, coldness, smoothness, etc.' (1993, 43). For Kant (1974), taste and smell affect our enjoyment of an object rather than knowledge of it, and are therefore subjective and inferior. The European tradition of landscape aesthetics has been strongly driven by visual apprehension, to the absence of the other senses, thereby marginalising the human and vegetative bodies of settler nations and imposing an aesthetics unfit for, and oftentimes destructive to, the Australian flora. 


\section{Flora and the Human Senses: Postcolonial Aesthetics of the Body}

Is it possible to describe a corporeal aesthetics as the eliding of temporal, spatial, sensory, bodily, and even cultural constructions? Instone (2004) argues for 'multilayered, multivalent, embodied and situated' (131) approaches to postcolonial cultural geographies of Australian nature. In Instone's view, situated knowledge evolves from a multilayered methodology that expresses the inherent complexities and tensions of doing cultural research on ecology. The interviewees in this project vary in their views on how and under what conditions a corporeal aesthetics develops. For Allan Tinker, aesthetics is a weak mode of perceiving landscape, and the visual appreciation of the flower is given complexity through the disclosure of botanical science, but not explicitly through embodied experience. For Merle Bennett and Lyn Alcock, aesthetics is broadened by sensory perception that requires walking and engaging bodily in the environment of the flowering plants. Kevin Collins exhibits a hybrid point-of-view that draws from plant science and multi-sensory appreciation, as he educates the public through touching, smelling, listening and even tasting the nectar of the flower. In the interviews, a pan-sensory aesthetic of flora incorporating the five senses is furthermore widened to incorporate the metasenses. Steven Hopper describes the relationship between sense of place and plants, or the creation of floratopaesthesia, and the nexus between memory and flora. A wildflower walk at the Fitzgerald River National Park binds sense of movement and plants in a metasense that can be termed florakinaesthesia. Additionally, Merle Bennett suggests the sense for the passage of time as it relates to the flowering of plants, or floratemporaesthesia.

Lyn Alcock, an amateur orchidologist and Dryandra enthusiast, epitomizes the infusion of nuanced bodily perceptions of flora into diction. The 'aesthetic language' 
of plants as such is the written or spoken diction that conveys sensory experience, impressions or attitudes towards flora. The reading of aesthetic language is an important approach for developing a corporeal aesthetics. Aesthetic language reveals values, attitudes and perceptions of plants and the landscape. As Lyn describes:

I think because the bushes are so harsh, so prickly, so most people don't like Dryandras when they see the bushes and yet when they have these flowers on them, some of them are so delicate and so magnificent and they only occur in Western Australia (Alcock 2009).

For Lyn, the juxtaposition of harshness and delicacy makes the Dryandra sensuously intriguing and iconic of the Southwest region. Lyn's statements demonstrate language infused with sight and touch and recognition of the regional uniqueness of plants such as the Dryandra through both their tactile and visual qualities.

The possibility of a corporeal aesthetic of plants takes into perceptual account connectivity amongst the senses and between the human experience of flora and the landscape. Corporeal engagement with flora describes a sensorium distributed throughout the multiple sense faculties that signifies the co-extensivity between the plant corpora and the human body. ${ }^{3}$ Plants are not only visually beautiful, stunning, or pretty, they are moreover edible, audible, palpable and olfactory. Additionally, the visuality of flower form and colour is linked to adaptations evolved by a venerable vegetation over time, as well as seasonal conditions and interactions with of other flora and fauna. The distinction between aesthetic visualism and experiential corporeality is the difference between an aesthetics of sense heterogeneity and connectivity and an aesthetics of surface appreciation and distance, which reduces the complexity of plants to visual apprehension.

A corporeal aesthetics of plants is necessarily one of connectivity between human experience and the landscape through the body. According to Rose and Robin (2004), 
ecological connectivity takes place amongst corporeal forms. Connectivity between humans and plants and between the senses themselves disrupts distanced visual evaluation by implying human and plant bodily and sensory intermeshing. Whereas aesthetic visualism inhibits the integration of the senses in the appreciation of flora through the juggernaut of sight, corporeality is a multi-sensory aesthetics of ecological connectivity within postcolonial landscapes like the Southwest of Australia. Within an embodied aesthetics, sense experience takes on a distinctly ecological pattern: interwoven rather than reduced, diachronic rather than limited to peak visual instances, and synergistically or even synaesthetically effective rather than imagistically induced. As Rose and Robin (2004) assert, a language of bodily engagement with flora communicates multivalent sense reality embedded into the human appreciation of plants in a place.

Corporeality recognises the limitations, historic and experiential, of the purely visual evaluation of plants and pushes aesthetics into the possibility of aesthesis beyond the evanescence of the flower. Perception beyond the purely visual, through the five senses-but more expansively through the body, movement, and time-makes possible a bodily-engagement and patterned, seasonal appreciation of plants. While spring is commonly considered the 'wildflower season', flowers occur throughout the year in the Southwest and some plants, such as many species of Banksia, only flower in the hottest and driest months. In addition to a year-round succession of flowering in the region, the leaves and bark of many plants change colour in response to heat stress. Southwest botanist Alex George uses the term 'diallagy' to define the ability of plants in change leaf and bark colour and re-green their foliage when rainfall resumes 
(George 2002). Hence, the Southwest landscape is always pan-sensorily, corporeally possible outside of the short, intense window of the spring wildflower tourism season.

In addition to experience of the five commonly accepted senses, we may consider four corporeal metasenses: topaesthesia, coenaesthesia, kinaesthesia and temporaesthesia. Socrates in Plato's Theaetetus suggested the unboundedness of the senses, 'a great number which have names, an infinite number which have not' (quoted in Connor 2008). Hence, we can discuss the metasenses with respect to the human experience of plants. To begin with, the sense for plants often determines sense of a place, or topaesthesia. George Seddon's 1972 classic Sense of Place discusses extensively the native plant taxa of the Southwest of Australia in characterising the region's distinctiveness. Considering his botanical field notebooks on Southwest rock outcrops compiled over three decades, professional botanist Steven Hopper suggests the nodes between memory, indigenous flora and the formation of topaesthesia:

The written notes are the same as travel journals written by people in notebooks forever, but I combine that with these collections of plants and to me it's quite a compelling way of bringing me right back to the space and place [of the rock outcrop] (Hopper 2009).

Topaesthesia, according to Solnit (1994), is a metasense composed of the perception of space and the faculty of memory. For Solnit, topaesthesia is also corporeal cognition, or the body's internal orientation consisting of the recollections of the past, the direct sensory perception of the present, and the cartographic possibility of the future. Sense of place in Solnit's terms locates the human body amongst the more-than-human bodies of the world-vegetative, animal and fungal. Floratopaesthesia, as suggested by Seddon, Hopper and Solnit, is the sense of place evoked through the experience of plants. 
There are the senses of one's body in space, one's body moving through space, and temporality in relation to plant life. Michel Serres notes these seventh and eighth senses. Coenaesthesia is the internal sense of one's body occupying space, such that 'if I close my eyes, I have a sense of my own body' $(2002,199)$. Additionally, kinaesthesia is the sense of walking, leaping or turning through space (Serres 2002). Florakinaesthesia henceforth refers to the sense of moving through the plant corpora through the basic acts of walking, running, crawling or bounding. A ninth sense might be described as temporaesthesia, or the sense of the seasonal passage of time. Floratemporaesthesia then indicates the sense for the seasonal passage of time through the successional experience of plants in a place. Barbara York Main's Between Wodjil and Tor (1967) evidences this sense by tracing the symphonic progression of plants through the seasons on a parcel of remnant bush in the Wheatbelt of Western Australia. Moreover, a Southwest aesthetic sensibility in Seddon's writings over a thirty year span shows the engendering of sense of place through protracted contact with the flora of place (Seddon 1972; 2005).

\section{Cultural Botany: An Ecotone Between the Humanities and the Botanical Sciences}

Embodied research into the appreciation of wild plants calls for a new context for studying human and plant engagement. The prevailing models for plant-human research that employ ethnographic methods are largely housed within ethnobotany or cultural ecology. I suggest the limitations of the ethnobotanical model and highlight the potential to expand cultural ecology to 'cultural botany'. The new context of cultural botany draws from the ethnographic and spatial methodologies of the social sciences, the analytic and textual strengths of the humanities, and the taxonomic and ecological understandings of botanical science towards a more-rounded and multi- 
faceted articulation of the interactions between human culture and botanical communities.

A recent corpus of literature in cultural ecology and human geography, which can be extended to the study of wildflower tourism and aesthetic experience of plants, points to the use of ethnographic methods for articulating human engagements with cultivated flora. Head (2007) in a review of the field of cultural ecology urges the use of 'a battery of diverse methodologies' (843) for interrogating cultural variables between plant communities and humans. Hitchings (2003) used ethnographic interviewing of gardeners in London to understand the multivalent perceptions of the materiality of cultivated garden plants. Hitchings and Jones (2004) describe 'research about plants with plants' (8) as an approach to studying human perceptions of botanical gardens using mobile interviews, or interviews and observations done while walking with people amongst plants. For Hitchings and Jones, mobile ethnographic practice encourages a bodily encounter with plants that introduces taste, smell, touch and sound into plant research. Head and Atchinson (2009) in their review of recent research into human-plant geographies enumerate several studies in which ethnographic methods allow people to 'talk about or demonstrate everyday embodied interactions with plants' (239). The accounts of embodied engagements, in the view of Head and Atchinson, are more intimate and sensorily rich in comparison to studies using conventional biogeographic or social science methods.

The application of ethnographic practice to the study of uncultivated, non-garden plants and the development of human-plant cultural research have been historically within the domain of ethnobotany. The term 'ethnobotany' was conceived in 1895 by 
the American botanist John William Harshberger to refer to the 'use of plants by aboriginal people' (cited in Cotton 1996). No longer solely concerned with the use of plants by traditional peoples, ethnobotany is the fusion of the methodologies of anthropological social science and botanical science for enquiry into the human-plant relationship (Martin 1995). Participant observation in ethnobotanical studies involves the researcher's direct participation in the informant's activities and rituals incorporating plants, such as farming, food preparation and gathering or initiation ceremonies (Martin 1995). Semi-structured interviews elicit information about a cultural view of flora through a conversational format that allows people to describe their lives, environment and relationship to certain plant species and botanical practices. The two methods work together effectively. As Martin (1995) argues 'Interviews can give us good ideas of the ways people describe their lives and their natural surroundings while participant observation allows us to see how people put their knowledge into practice' (96). Ethnobotany uses both qualitative and quantitative strategies drawn from anthropology and botany to understand the usage and perception of plants by human cultures.

Ethnographic methodology has a long-standing history of use in ethnobotany for documenting the role of plants in the everyday activities of a cultural group and eliciting the life histories of individuals in relation to flora. Ethnography refers to a particular set of qualitative methods used in both cultural studies and the social sciences to learn about people's lives and elucidate certain cultural phenomena and meanings (Hammersley \& Atkinson 1995). The groups studied produce accounts of their world that are pertinent in explaining broader social and cultural topographies. 
Brewer defines ethnography-as-fieldwork that requires the direct participation of the researcher in the social milieu under study:

Ethnography is the study of people in naturally occurring settings or 'fields' by means of methods which capture their social meanings and ordinary activities, involving the researcher participating directly in the setting, if not also the activities, in order to collect data in a systematic manner but without meaning being imposed on them externally $(2000,10)$.

Brewer is describing participant observation, which situates the researcher within the environment, settings, activities and rituals of the cultural group. Participant observation differs from prescribed ethnographic interviews that use direct questioning as a means of acquiring data on cultural meanings and practices. Ethnographic interviews, unlike participant observation, tend to demarcate a setting, informant and other variables, focusing on these controlled elements to provide insight and information that would otherwise be difficult to obtain. Interviewing is an effective methodology if meanings are encoded in the cultural practice itself and are thus hard to identify and articulate by the researcher. As Hammersley and Atkinson note on the utility of using both approaches together, 'There are distinct advantages in combining participant observation with interviews; in particular, the data from each can be used to illuminate the other' $(1995,131)$. Interviews extend actual participation and observation in the ritual or practice.

Considering its origins in botany and anthropology, ethnobotany is strongly characterised by a quantitative, objective emphasis inherited from those traditions. Ethnography, especially the written discourses coming out of ethnographic studies within the social sciences, has long been held as neutral, objective representation of cultural realities (Pratt 1986). As Pratt posits, 'It is possible to suggest that ethnographic writing is as trope-governed as any other discursive formation' (1986, 28). The fusion of objective and subjective practices and the presence of the authorial 
voice of the researcher in the ethnographic account are argued for extensively by Geertz (1988). An insider approach not only situates the researcher within the culture, in the sense of participant observation, but also re-examines the representation of culture in ethnographic practice in what Geertz (1988) refers to as 'I-witnessing'. Ethnography, beyond its social science emphasis, is seen increasingly as an interdisciplinary approach to the description and critique of culture, drawing from cultural and literary theory in particular (Clifford 1986).

The discipline of ethnobotany with its roots in the social and natural sciences has been linked especially to ethnological anthropology. However, the study of the human-plant affinities transcends disciplinary fields and invariably becomes interdisciplinary in approach. Cultural, literary and arts-based perspectives afford opportunities for understanding perceptions of plants and the role of flora in culture. 'Cultural botany' therefore refers to the application of humanities and cultural ecology perspectives and methodologies to the study of the human relationship to plants. Cultural botany concerns the worldview that groups develop towards flora, as well as the artistic, literary, philosophical and cultural practices that engage, invoke, interpret or rely upon plants.

\section{Visual Aesthetics and Scientific Knowledge Production: Lesueur-Eneabba}

Cultural botany, rather than the social or botanical sciences, is a fruitful context for applying ethnographic practice to the study of indigenous plants. The tension, however, between embodied experience of nature and scientific knowledge production is a long-standing issue in aesthetic philosophy of landscape. Unlike colonial science scholars like Pratt (1992) and Driver (2004) who argue for the corporeal production of 
scientific knowledge, I have asserted that scientific taxonomic knowledge is visually deduced and lies in contradistinction to an embodied aesthetics of flora. The cognitive theory of environmental aesthetics takes the position that ecology, botany and other natural sciences comprise the appropriate structures for appreciating the natural world (Brady 2003). Carlson (1993) asserts that the 'natural environmental model' makes possible the distinction between the designed object of art and the ordered object of nature. Whereas the designed object of art appreciation exists on its own, an ordered object of nature does not stand apart from natural science as its narrative of creation (Carlson 1993). Carlson's model establishes contingency between the probity of aesthetic experience and the narrative provided by taxonomic botany. His model excludes nuanced, multiple sensory experience and the participatory body, or what Serres (2008) terms 'mingled bodies', in the appreciation of plants. Moreover, the visualistic origins of natural science present an impasse to a pan-sensory, embodied aesthetics. Michel Foucault (2002) links visualism to the natural sciences in which seeing and saying are bound as a condition of classificatory natural history, leaving the naturalist concerned with the structuring of the visible world rather than embeddedness and sense experience.

An ethnographic enquiry into Lesueur-Eneabba, a floristically significant heathland ecosystem, provides a case study of the tensions between botanical science and the aesthetic appreciation of flora. Lesueur National Park itself has over nine hundred species of plants, or ten percent of Western Australia's identified flora, and ranks as one of the three most critical areas for flora conservation in the region (Department of Conservation and Land Management, 1995). The park lies at the northern limit of the kwongan, a Mediterranean-type shrubland, occurring only in the Southwest and 
exhibiting some of the most complex vegetation patterns in Australia (Department of Conservation and Land Management, 1995). Allan Tinker, proprietor of Western Flora Caravan Park in Eneabba, states that the kwongan has become a pocket of biodiversity in a land severely altered by clearing:

We're down to three percent of the richest heathlands in the world left intact and that's very, very noticeable...These are now termed as vegetative islands. That's what they've become. They're an island in a landscape that is now being used for other purposes (Tinker 2009).

Kwongan derives from the local Noongar language and indicates 'sandy country with open scrubby vegetation' (Beard and Pate 1984, xvii). However, as the term 'scrub' is used pejoratively to denote worthless bushland, Allan Tinker's description of kwongan as bush that is the height of the eye is preferred, insofar as it links bodily metaphor and measurement to landscape (Tinker 2009).

Historic and contemporary representations of the Lesueur-Eneabba area evidence the conjunctions between visualism, natural science and emerging aesthetic attitudes towards flora. Driver (2004) raises questions about the authority of the landscape observations of early explorers and argues that the veracity of documents such as journals might have been affected by forms of field disturbance-madness, illness, starvation or even difficulties with the process of recording information. However, the kwongan is consistently depicted in less-than-favourable terms, mostly based in the sense of sight, in the journals of several European explorers of the Lesueur-Eneabba region, suggesting that, rather than disturbance, the journals express commonly held values of landscape aesthetics. Nicolas Baudin, the post captain who kept a detailed journal aboard the Naturaliste in 1801 deduces from the distant perspective that the barren harshness of the landscape signifies a commensurately low significance to their natural history purposes: 
As this coast appears to be of no interest for navigation and even less for Natural History, I did not think it necessary to stop there...I merely took some views of the coast, which will give a most accurate idea of what it can be like (Baudin 1974, 200).

Explorers who travelled overland, through the landscape, rather alongside it from the perspective of a sailing vessel, depicted the sand plains with even less complimentariness. In his southward traverse of the kwongan from the Arrowsmith River to Perth, explorer George Grey in 1837 refers to 'waste and barren plains' (1841, 59), 'arid and barren in the extreme' $(1841,66)$ and of a 'bare, sterile, and barren nature' $(1841,118)$. Approaching Mount Lesueur from the south, English-born explorer A.C. Gregory wrote in 1848 that 'the country traversed almost wholly worthless sand and scrub' $(1884,29)$ and that 'the hills produced little besides coarse scrub...the land [on the banks of the Hill River] was very scrubby and indifferent' $(1884,29)$.

The early explorers remarked on the visual character of the Lesueur-Eneabba landscape, or the perceptual constitution of its space. The evaluations of Baudin, Grey and Gregory reveal aesthetic values and evaluations based in sight, which fasten the outward appearance of the kwongan to sterility, indifference and worthlessness. The visually deduced assignment of value extends into contemporary scientific studies of the landscape. The Lesueur Management Plan of 1995-2005 includes a study of landscape character that identifies vegetation types of high, moderate and low scenic, or aesthetic, value. The values are assigned according to perspectival contrasts between focal point plants that stand out in an otherwise undifferentiated vegetation. Single trees or shrubs that become focal points in the landscape are classified as high scenic quality. Other floral patterns of high aesthetic quality include purely visual assessments of the "windshaped, gnarled or dwarfed vegetation unusual in form, colour or texture' (Department of Conservation and Land Management, 60). Areas where 
high botanical diversity is signified by unique colour or textural patterns are further valued. Of moderate and low aesthetic value are floral patterns without distinguishable scenic or visual characteristics of texture, form colour or structural variation (Department of Conservation and Land Management 1995, 60).

The conjunctions between visuality, science and scenic values extend to Allan Tinker's presentation of floral aesthetics, which typifies the natural environmental model of Carlson and the scientific basis for an aesthetics of flora. Tinker explains the symbiotic relationship between the smoke bush (Conospermum spp.) and the native bee that pollinates it in lavish detail. He illuminates the visual anatomical differences in seed structure between the Hakea and Grevillea even though the majority of tourists have come solely to view pleasing wildflowers. For Tinker, an aesthetic view of plants-their prettiness or suitability for photographs-is superficial, visual engagement with flora. Science provides, in Tinker's terms, 'The reality of what [the visitors] are missing out there' (Tinker 2009). Through an exegesis of plant physiology and ecology, sighted apprehension is given meaning, substance and complexity. The science of pollination, ecology of fire and the relation between geomorphology and plant life deepen how humans regard, and ultimately conserve or destroy, the botanical world.

\section{Corporeal Aesthetics and the Metasenses: Fitzgerald River National Park}

A wildflower show is a collaborative, community-wide celebration of local botanical diversity, yet it is strongly ocularcentric, unlike a wildflower walk. Since 1982, Ravensthorpe between Albany and Esperance, W.A. has been home to, arguably, the largest wildflower show in the world according to the number of plants on display 
(Bennett 2009). Each year, between 700 and 800 different species of flowering plants are brought in from the surrounding bushland by a team of volunteers, then meticulously placed in bottles, transformed into imaginative creations, and arranged according to taxonomic family in the Ravensthorpe Senior Citizens Centre. The presentation of the native flora is equally important to the taxonomic layout of plants on the tables. Merle Bennett, coordinator of the show, refers to the importance of using 'visual images' and 'species which are colourful and eye-catching' to draw in the attention of visitors (Bennett 2009).

The Ravensthorpe Wildflower Show showcases the flora of the Fitzgerald River National Park, located on the central south coast of Western Australia between Hopetoun on the eastern boundary and Bremer Bay on the western side. The park contains approximately 1,800 'beautiful and bizarre species of flowering plants' or about twenty percent of the total flora of Western Australia and forty-two percent of the species of the Southwest Botanical Province (Fitzgerald River National Park Advisory Committee 1987). The Park has three times the number of species found in the United Kingdom and half of the floral count of South Australia. Sixty-two plant species are found only within the park limits and another forty-eight are more or less limited to the park, which is unusually floristically dense for a three hundred thousand hectare land area (Department of Environment and Conservation, n.d.).

The area's botanical diversity and beautifully bizarre plant species were unremarkable to early European explorers, who instead commented on aridity and apparent sterility of the landscape. In 1802, Matthew Flinders aboard the Investigator made reference to the three prominent peaks in the Park: West, Middle and East Mounts Barren (Flinders 
2000). On his westward traverse of the Great Australian Bight and Nullarbor Plain from Adelaide to Albany in 1841, John Eyre comments disparagingly on the 'sterile country' (Eyre 1964). He describes the Park's most prominent land feature and its surrounding landscape as 'Most properly had it been called Mount Barren, for a more wretched aridlooking country never existed than that around it' (Eyre 1964). However, as with the journals of Baudin, Grey and Gregory in the LeSueur-Eneabba region, the consistently gloomy reactions to the Fitzgerald River landscape point to something greater than disturbance in the field experience of the explorers, as suggested by Driver (2004).

Unlike Eyre and Flinders, Bennett is someone who has forged a significant longstanding connection to the Fitzgerald River landscape. Her interview exudes allusions to the bodily metasenses of Solnit and Serres. Bennett's sense of place, or topaesthesia, is formed in part by her precise local knowledge of where to locate plant species and when they might be in bloom. When asked of the seasonality of flowering and the potential for tourism outside of the spring flush, Bennett charts the calendrical progression of the year to the arrival of orchids, thereby evidencing the metasenses, topaesthesia and temporaesthesia:

In the summer you get the sun flowers, the Thelymitras, which are always later. They won't open unless the sun is shining. They're late. Then some of the Drosophyllums are quite late as well. But then you get the Caladenia, the leafless orchid, which is one of the, is a winter flowering orchid. You have the Eriophyllas, they're probably the first ones in about March, April, and the hare orchids about the same time, then you get into the Pterostylis - the snails, and the midgets, and the greenhoods generally (Bennett 2009).

Unlike Tinker, for whom science is the primary mode for deepening the aesthetic experience of the flower, Bennett calls for the engagement of the body and the sense of movement through the vegetation, or florakinaesthesia. When asked what kind of perception might be required to appreciate the plants of the region, Bennett responds: 
On the whole, people need to stop and get out of their vehicles, to walk rather than to just expect to see the walls of everlastings that occur up north... On the whole, you don't get these great masses of one thing flowering [here] (Bennett 2009).

We move through botanic bodies through the commonplace activity of walking. Solnit (2000) cogently characterises walking as an antidote to the frenzied pace that inhibits slow appreciation. Walking is corporeal knowing-and a methodology of embodiment, as Solnit suggests- that reclaims a lost cultural history of the body, 'a half-abandoned landscape of ideas and experiences' $(2000,12)$. However, walking that is temporal, spanning the seasons and under different climatic conditions, provides a more-rounded multi-sensory experience of a place. Although the early explorers to present-day LeSueur and Fitzgerald River National Park walked upon the land, the record they left in their journals speaks in visual terms of the perceived bleakness and infertility of the vegetation. Walking for Eyre produced an inscription limited to a few days during a single season, rather than temporally throughout the seasons. Ingold (2000) defines embodiment in terms of motion as 'incorporation rather than inscription, not a transcribing of form onto material but a movement wherein forms themselves are generated' (193). For Ingold, the body is a living instrument, a walking methodology that rivals the surveyor's instruments in the field. In this sense, a wildflower walk, such as the Friends of Fitzgerald River National Park Coastal Bushwalk, as corporeal experience augments the relatively narrow sensory experience of the wildflower show. 4

Whereas a wildflower show is the bringing in of living plants from the wild into the private sphere of the church or community centre, a wildflower walk is the seeking out of plants in their native habitat and on their own terms. A wildflower show engages the sense of sight but rarely the senses of smell, touch, sound and taste. A wildflower walk, however, is the practice of kinaesthesia and flora. The pace of one's body 
depends upon the terrain and the character of the plant life. If the vegetation is thick and prickly, the group slows and surveys the horizon for alternate walking routes. Whilst the wildflower show might select ideal examples of a flowering plant, a wildflower walk reveals plants at varying states of growth, decay, flowering, fruiting or seeding.

\section{Conclusion}

How does ethnography contribute to the development of a corporeal aesthetics of plants? In the beginning of this essay, I made two interrelated claims. Firstly, a corporeal engagement with indigenous plants invokes the full horizon of human senses through human and plant bodies as a postcolonial aesthetics of flora. Secondly, ethnographic practice is an effective and productive methodology for developing a corporeal aesthetics by revealing human perceptions of wildflowers at Southwest Australian sites of high botanical diversity.The use of ethnography for investigating the question of aesthetics and botanical biodiversity has circumscribed the parameters of a multi- and metasensory corporeal aesthetics of wild flora through the context of cultural botany and independently of ethnobotanical social or scientific research paradigms. Through readings of the aesthetic language in interview transcripts as well as in the journals of explorers and the managerialist language of planning documents, the distinction between visual appreciation and corporeal engagement emerges.

Extending recent research in cultural ecology, participant observation augmented semi-structured interviews in the attempt to understand aspects of the aesthetic experience of wildflowers within cultural botany. Whilst botanical science deepens 
cognitive knowledge of plants, as suggested by Tinker, its visualistic tendencies present a hindrance to a diversified aesthetics of the body. The experience of flora based in the corporeal senses and metasenses broadens aesthetic value and establishes a further direction for studying the multivalent intersections between humans and plants. Through a corporeal aesthetics, in post-colonial Australian landscapes, the management of botanical reserves and the interactions of plants and society are not assessed solely through the visual assignment of value, but also through how the landscapes smell, taste, sound, or feel and how one moves through them The further elaboration of cultural botany will adopt and modify methodologies from the humanities, arts and cultural ecology research to provide insights beyond those pertaining to landscape aesthetics and embodiment theory.

\section{Acknowledgements}

I would like to thank my $\mathrm{PhD}$ Supervisor, Dr. Rod Giblett and my Associate Supervisor, Dr. Lekkie Hopkins at Edith Cowan University. Also, the two anonymous referees were exceptionally helpful and insightful and to them I give my sincerest thanks.

\section{References}

Alcock, Lyn. 2009. Interview by John Ryan. Digital recording. September 8. Stirling Range Retreat, Borden, WA.

Baudin, Nicolas. 1974. The journal of post captain Nicolas Baudin Commander-inChief of the Corvettes GEOGRAPHE and NATURALISTE. Adelaide: Libraries Board of South Australia.

Beard, John S. and John S. Pate. 1984. Foreword. In Kwongan: Plant life of the sandplain, ed. J. S. Pate and J. S. Beard, xvii-xxi. Nedlands, W.A.: University of Western Australia.

Bennett, Merle. 2009. Interview by John Ryan. Digital recording. September 13. Hopetoun, WA.

Brady, Emily. 2003. Aesthetics of the natural environment. Tuscaloosa: The University of Alabama Press. 
Brewer, John D. 2000. Ethnography. Buckingham: Open University Press.

Carlson, Allen. 1993. Appreciating art and appreciating nature. In Landscape, natural beauty and the arts, ed. S. Kemal and I. Gaskell, 199-227. Cambridge, UK: Cambridge University Press.

Clifford, James. 1986. Introduction: Partial truths. In Writing culture: The poetics and politics of ethnography, ed. J. Clifford and G.E. Marcus, 1-26. Berkeley, CA: University of California Press.

Collins, Kevin. 2009. Interview by John Ryan. Digital recording. September 9. Banksia Farm, Mt. Barker, WA.

Connor, Steven. 2008. Introduction. In The five senses: A philosophy of mingled bodies. by Michel Serres, 1-16. London and New York: Continuum.

Corrick, Margaret G., and Bruce A. Fuhrer. 2002. Wildflowers of southern Western Australia. Noble Park, VIC: The Five Mile Press.

Cotton, C. M. 1996. Ethnobotany: Principles and applications. Chichester, Eng.: John Wiley \& Sons.

Department of Conservation and Land Management. 1995. Management plan: Lesueur National Park and Coomallo Nature Reserve 1995-2005. Perth, W.A.:

Department of Conservation and Land Management.

Department of Environment and Conservation. n.d. Fitzgerald River National Park. http://www.dec.wa.gov.au/hotproperty/property/national-parks/fitzgerald-rivernational-park.html. (accessed 5 October 2009).

Driver, F. 2004. Distance and disturbance: Travel, exploration and knowledge in the nineteenth century. Transactions of the RHS 14: 73-92.

Eyre, Edward J. 1964. Journals of expeditions of discovery into Central Australia, and overland from Adelaide to King George's Sound, in the years 1840-1.

Adelaide: Libraries Board of South Australia.

Fitzgerald River National Park Advisory Committee. 1987. An introduction to the Fitzgerald River National Park. Perth, WA: The Committee.

Flinders, Matthew. 2000. Terra Australis: Matthew Flinders' great adventures in the circumnavigation of Australia. Melbourne: Text Publishing.

Foucault, Michel. 2002. The order of things: An archaeology of the human sciences. London: Routledge.

Geertz, Clifford. 1988. Works and lives: The anthropologist as author. Stanford, CA: Stanford University Press. 
George, Alex. 2002. The long dry: Bush colours of summer and autumn in Southwestern Australia. Kardinya, WA: Four Gables Press.

Giblett, Rod. 2004. Living with the Earth: Mastery to mutuality. Cambridge, UK: Salt.

Gregory, Augustus C. \& F. T. 1884. Journals of Australian explorations. Brisbane: James C. Beal, Government Printer.

Grey, George. 1841. Journals of two expeditions of discovery in North-West and Western Australia during the years 1837, 38, and 39. Vol. 2. London: T. and W. Boone.

Hammersley, Martin \& Paul Atkinson. 1995. Ethnography: Principles in practice, $2^{\text {nd }}$ edition. New York: Routledge.

Head, L. 2007. Cultural ecology: The problematic human and the terms of engagement. Progress in Human Geography 31, no. 6: 837-846.

Head, L and J. Atchison. 2009. Cultural ecology: Emerging human-plant geographies. Progress in Human Geography 33, no. 2: 236-245.

Head, Lesley and Pat Muir. 2007. Backyard: Nature and culture in suburban Australia. Wollongong, NSW: University of Wollongong Press.

Hegel, Georg W. F. 1993. Introductory lectures on aesthetics. ed. M. Inwood and trans. B. Bosanquet. London: Penguin.

Hitchings, R. 2003. People, plants and performance: On actor network theory and the material pleasures of the private garden. Social and Cultural Geography 4, no. 1: 99-113.

Hitchings, R and V. Jones. 2004. Living with plants and the exploration of botanical encounter within human geographic research practice. Ethics, Place \& Environment 7, no. 1 \& 2: 3-18.

Hopper, Steven. 2009. Phone interview by John Ryan. Digital recording. 9 September.

Ingold, Tim. 2000. The perception of the environment: Essays in livelihood, dwelling and skill. London and New York: Routledge.

Instone, L. 2004. Situating nature: On doing cultural geographies of Australian nature. Australian Geographer 35, no. 2: 131-140.

Kant, Immanuel. 1974. Anthropology from a pragmatic point of view. The Hague: Nijhoff.

Lindley, John. 1840. A sketch of the vegetation of the Swan River colony. London: James Ridgway.

Main, Barbara York. 1967. Between wodjil and tor. Perth, WA: Landfall Press. 
Martin, Gary J. 1995. Ethnobotany: A methods manual. London: Chapman \& Hall.

Pratt, Mary L. 1986. Fieldwork in common places. In Writing culture: The poetics and politics of ethnography, ed. J. Clifford and G.E. Marcus, 27-50. Berkeley, CA: University of California Press.

---. 1992. Imperial eyes: Travel writing and transculturation. London and New York: Routledge.

Rose, D. B. and L. Robin. 2004. The ecological humanities in action: An invitation. Australian Humanities Review 31-32.

Ryan, J. 2009. Why do extinctions matter? Mourning the loss of indigenous flora in the Southwest of Western Australia. Philament 15: 51-80.

Seddon, George. 1972. Sense of place: A response to an environment, the Swan Coastal Plain, Western Australia. Perth, WA: University of Western Australia Press.

---. 2005. The old country: Australian landscapes, plants and people._Port Melbourne: Cambridge University Press.

Serres, Michel. 2002. The art of living: A conversation with Michel Serres. In Hope: New philosophies for change, ed. M. Zournazi, 192-208. Annandale, NSW: Pluto Press.

---. 2008. The five senses: A philosophy of mingled bodies. London and New York: Continuum.

Solnit, Rebecca. 1994. Savage dreams: A journey into the landscape wars of the American West. Berkeley, CA: University of California Press.

---. 2000. Wanderlust: A history of walking. New York: Penguin Books.

Tinker, Allan. 2009. Interview by John Ryan. Digital recording. August 29. Western Flora Caravan Park, Eneabba, WA.

Western Australian Tourism Commission. 2003. Research into the wildflower tourism industry: An exploration of consumer and industry perceptions.

http://www.tourism.wa.gov.au/Research_and_Statistics/Specialised_Research/ Pages/Wildflower_research.aspx. (accessed 27 October 2009). 


\section{Notes}

${ }^{1}$ For further information, see Collins, Kevin, Kathy Collins \& Alex George. 2008. Banksias. Melbourne, VIC: Bloomings Books.

${ }^{2}$ For an overview of the Southwest Botanical Province, see Hopper, Steven. 1993. Kangaroo paws and catspaws: A Natural history and field guide. Como, WA: Department of Conservation and Land Management.

${ }^{3}$ For a more detailed proposal of the concept, see John Ryan 'Plants that perform for you? From floral aesthetics to floraesthesis in the Southwest of Western Australia' Australian Humanities Review (AHR), November 2009.

${ }^{4}$ Bushwalk held on 13 September 2009. For more information about the organization, see www.fitzgeraldfriends.org.au 